\section{Estratégias para Divulgação da Produção Técnico-Científica em Epidemiologia *}

\author{
José da Rocha Carvalheiro **
}

Diante das reiteradas propostas de elaboraçāo de um Plano Diretor para o Desenvolvimento da Epidemiologia, o A. analisa as dificuldades inerentes à construção do seu objeto. $O$ arcabouço teórico-metodológico da "nova" Epidemiologia é contrastado com as necessidades de ampliação do uso da disciplina a nível dos serviços de saúde, geralmente como arma do planejamento das ações. Passando por consideraçōes a respeito dos pólos científico e técnico, no caso peculiar de uma disciplina que tem socialmente determinados os problemas com que se defronta e a urgência das respostas exigidas, o A. considera o meio acadêmico lugar privilegiado, mas não exclusivo, onde se elaboram as respostas. Ao considerar a estratégia de divulgação dos avanços obtidos, o A. lembra que, além da produção acadêmica consolidada em livros $e$ artigos de revista, há que levar em conta a literatura fugidia, tâo comum nesta área do conhecimento. Comenta a incipiência da divulgação sistematizada da informação relevante produzida em teses $e$ dissertaçōes. Conclui atribuindo à linha editorial da Abrasco papel saliente, no Brasil, no direcionamento da divulgação da produção epidemiológica. Propõe a consolidação desta linha editorial, sugerindo algumas alteraçōes.

Palavras-chave: Epidemiologia, Produção Epidemiológica, Divulgação em Epidemiologia.

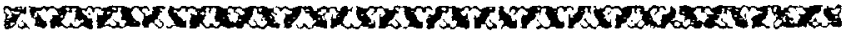

\section{INTRODUÇÃO}

Sucessivas reuniões, promovidas pela Abrasco, Opas e outras entidades, tếm apontado a necessidade de elaborar um Plano Diretor para o desenvolvimento da Epidemiologia. Isto denota preocupaçāo dos profissionais da área, a ser contextualizada. Não é trivial uma disciplina científica encontrar-se tão mobilizada quanto a Epidemiologia para definir seus rumos. Em geral, estes vão sendo traçados num processo árduo Cadernos de Saúde Pública, RJ, 6 (3): 319-329, jul/set, 1990
* Originalmente apresentado na Oficina de Trabalho "Estrate gias para o Desenvolvimento da Epidemiologia no Brasil", Itaparica, Bahia. Financiamento: CNPq/Convénio Fiocruz.

\footnotetext{
* Professor Titular do Departamento de Medicina Social, Faculdade de Medicina de Ribeiräo Preto, USP. Diretor do Instituto Nacional de Controle de Qualidade em Salide INCQS/Fiocruz.
} 
de construção que desdenha as aplicaçōes, pouco importando se $\odot$ imediatismo pragmático está satisfeito ou não. Com a Epidemiologia latino-americana ocorre um fenômeno curioso, para dizer o menos. Articulouse, em anos recentes, como disciplina científica, ao redor de idéias demasiado ambiciosas para os estreitos limites da importância prática de medidas de intervençăo propostas para fazer face a doenças socialmente relevantes. Como esta tem sido a maneira usual de entender a Epidemiologia, criou-se um clima artificial de necessidade de afirmação da "nova" Epidemiologia em frce da brutalidade da situação concreta de saúde dos povos com os quais convivem os cientistas responsáveis pelas novas formulaçōes.

Um dos mais fortes indícios desta postura é dado pelas reiteradas afirmaçöes de que faz falta mais Epidemiologia nos serviços de saúde. O mito da incorporação da Epidemiologia no Planejamento, inclusive local, como fator indispensável à melhoria dos serviços e, por tabela, da saúde da populaçāo, deve ser destruído.

Conhecimento epidemiológico, para instrumentalizar a ação, não é tão escasso como faz supor esta postura melancólica e saudosista. Melancólica, porque pinta um quadro de quase insolvência da Saúde Pública atual, inerme por falta de ação da Epidémiologia. Saudosista, porque faz lembrar o período áureo da Epidemiologia Biológica que, desvendando ciclos dos parasitas, armou a Saúde Pública, sua contemporânea.

Levantar a produção científica da Epidemiologia exige um esforço historiográfico que remete, pelo menos, à Europa do século XVIII. Alguns, mais audaciosos, remetem-na à antiguidade clássica, atribuindo a Hipócrates papel saliente (Najera, 1984). Na verdade, tendo se instituído como disciplina acadêmica quando já ia razoavelmente avançado o século $X X$, torna-se assunto de especulação traçar as raízes remotas. Assim como se recupera o remotíssimo papel de Hipócrates, alguns epidemiologistas sociais nấo deixam por menos e atribuem a Engels e Marx o papel de iniciadores da Epidemiologia "científica", a verdadeira (Breilh, 1972). Torna-se mais compreensivel considerar o conhecimento como produto social, passar do cogito para nós cogitamos, partindo de uma situação objetiva, de um dado concreto, de um fato social que diretamente fixa e qualifica a posição de cada individuo singular num processo histórico (Vieira Pinto, 1979). Neste sentido, a aparente ironia, atribuída a Alexander Gilliam (Holland \& Karhausen, 1978), de que epidemiologia é o que fazem os epidemiologistas, näo é despropositada. Nấo é descartável a produção, pretérita ou contemporânea, de nenhuma das linhas de pensamento epidemiológico. Até porque uma ciência nova, mesmo 
revolucionária, começa sempre algures num determinado universo de conceitos e de palavras existentes, portanto histórica e teoricamente determinados; é em função de conceitos e de termos disponiveis que toda a teoria nova, mesmo revolucionária, deve encontrar com que pensar e exprimir a sua novidade radical (Althusser, 1978).

Foi pensando nessa complexa trama que hoje envolve (sempre envolveu!) a Epidemiologia que optamos por desenvolver o tema por etapas, decorrência imediata da decomposição do seu enunciado em situação reversa: Epidemiologia; Técnico e Científico; Produção Técnico-científica; Divulgar produçāo técnicocientífica; Estratégia para divulgar a produção técnicocientífica em Epidemiologia. Da Epidemiologia demos conta nesta introdução, além do que perpassa os demais itens.

\section{TÉCNICO E CENTÍFICO (C\&T)}

Existe uma dinâmica própria ligando as tecnologias às ciências que lhes dão suporte. Esta interação recíproca nāo se dá num plano, mas num movimento helicoidal que avança no tempo. As hélices correspondentes às diversas áreas disciplinares interagem: uma tecnologia desenvolvida numa área atua sobre a "sua" ciência básica, sobre "outras" ciências e tecnologias. Sobredeterminando os processos simultâneos, a organização social, em particular o desenvolvimento das forças produtivas e das relações de produção. Estas idéias são mais claras quando se trata de tecnologias materiais (equipamențos e medicamentos, na área da saúde, por exemplo). É freqũente confundir os pólos científico e tecnológico quando se trata de tecnologias não-materiais. A discussão do próprio saber, enquanto tecnologia, já não é nova. $\mathrm{Na}$ área da Saúde, trabalho recente de Mendes Gonçalves (1986) envereda por esta linha, dando ao saber o sabor de tecnologia que organiza o trabalho nas unidades sanitárias. E comum uma tecnologia preceder o desenvolvimento da ciência que passa a lhe dar suporte. A Mecânica e a Física constituem o exemplo mais citado; a Epidemiologia Moderna parece seguir um padrāo semelhante, exigindo um esforço maior de reflexão em se tratando de tecnologia não-material.

Estas questões, na área da Epidemiologia, poderiam parecer mera fruição intelectual, não fora a viva discussão instaurada, às vezes com inusitada agressividade, entre várias vertentes do trabalho epidemiológico. Priorizar o componente gnosiológico ou o axiológico desta disciplina é uma opção do pesquisador. Retornando a Vieira Pinto (1979), o conhecimento epidemiológico é um fato social, um produto histórico, 
que fixa e qualifica a posição de cada investigador singular. Retornemos ainda a Althusser (1978) e à sua idéia de conceitos empíricos que "realizam" os conceitos teóricos no conhecimento concreto de objetos concretos. Podemos entrever que, no pólo tecnológico da Epidemiologia, precedendo e propondo a ação, há toda uma elaboração de dados empíricos transformados em matéria-prima dos conceitos empíricos pela intervenção de conceitos teóricos. (Mesmo sem aspas, a transcrição é quase textual). Sem aprofundarmos esta incursão pela teoria, podemos extrair uma idéia de importância para o nosso tema: quando se trata de divulgar a produção técnico-científica, os limites desta produção são amplos e relativamente imprecisos. Há, de fato, que traçar estratégias.

De qualquer maneira, o aprofundamento das reflexões há de dar conta de uma precisão cada vez maior das diversas instâncias articuladas, constituindo pólos que interagem dialeticamente no espaço metodológico (Bruyne et al, 1977). Tratando-se a Epidemiologia de uma disciplina de natureza peculiar, o pólo técnico do espaço metodológico, em razão de sua ligaçāo imediata com as aplicaçóes práticas, tende a ser enfatizado. Confunde-se, de fato, com o pólo tecnológico da concepção usual de relação entre a ciência e a técnica. Neste sentido, não é demais recordar o relativo desprezo dos filósofos da ciência em relação à tecnologia, assinalado por Bunge (1980). Tão mais estranho num momento histórico no qual a tecnologia tem um desenvolvimento e uma penetração em todos os campos jamais exibidos anteriormente. A Epidemiologia deverá beneficiar-se de um aprofundamento das reflexões sobre a filosofia da tecnologia, uma vez que - componente axiológico deverá merecer especial atenção $\mathrm{e}$, talvez, dar resposta às freqüentes indagações quando ao valor da nova Epidemiologia. Pela própria natureza da Epidemiologia, os resultados concretos da aplicação dos seus conhecimentos, essenciais para a reflexāo teórica, ganham vida própria na medida em que as aplicações são socialmente prestigiadas quando têm sucesso. Voltaremos ao tema, porém antecipamos uma conclusão: a produção do saber epidemiológico (técnico-científico) não se dá apenas na academia: informações produzidas na realidade diária do funcionamento dos serviços de saúde, corretamente coletadas, são transformadas em dados que poderão ser selecionados e reduzidos a hipóteses teóricas precisas (usaremos os conceitos de informação, dado e fato dos já citados Bruyne et al, 1977). Decidir como trabalhar com esta imensa massa de informações, no contexto da divulgação da produção técnico-científica, faznos repetir: há, de fato, que traçar estratégias. 


\section{PRODUÇĀO TÉCNICO-CIENTÍFICA}

Jå assinalamos que, como qualquer outro processo produtivo, também a produção científica é social ("nós cogitamos"). Não há produção e produto que se possam desvincular de seu contexto, embora a sobredeterminação do global sobre o singular, do todo sobre as partes, não chegue a impôr fatalisticamente os rumos a seguir. Permanece sempre uma autonomia relativa dos processos específicos. No caso da produção C\&T da Epidemiologia, esta questão é muito clara. Os problemas são determinados socialmente em si e na urgência de sua interpretação. Cabe à Epidemiologia, como resposta, a objetivação dos problemas colocados. Ao formular as respostas, guarda uma autonomia relativa que se expressa em suas diversas tendências. Contextualizar ou não as propostas de intervenção não lhes altera a eventual eficácia, embora o mesmo não se possa dizer quanto à eficiência e efetividade. Os locais em que se dá a elaboração das respostas são os mais variados: a academia é apenas um lugar privilegiado. Também os serviços, a imprensa, os políticos e o próprio povo constroem suas respostas. Não há monopólio da produção C\&T em Epidemiologia: ao contrário da fusâo nuclear a frio que exige a sofisticação acadêmica.

Essa massa informe de respostas constitui, num momento dado, o saber (os saberes!) epidemiológico. Circula com mecanismos próprios, diversos, às vezes inusitados. Considerar isto tudo como produção $C \& T$ em Epidemiologia traz, de novo, o mote: há, de fato, que traçar estratégias.

\section{DIVULGAÇĀO DA PRODUÇÃO C\&T}

Existe um preconceito de que a ciência deveria ter a primazia da divulgação, porque é ela quem detém a verdade. $\mathrm{Na}$ prática, a ciência não domina os meios de divulgação. Nunca o fez; agora, menos ainda. Há uma quantidade imensa de "lixo" pretensamente científico, com prioridade de divulgação.

Divulgar a produção científica tem, em todas as áreas do conhecimento, uma estratégia consolidada: publicar livros e revistas científicas. O tamanho do parque editorial, em particular o número de títulos de revistas científicas editadas, são indicadores muito prestigiados da produção científica de um país, ou de uma área disciplinar.

A produção científica latino-americana, na área de Saúde Coletiva, consolidada em publicações, tem sido objeto de intensa preocupação. Pelas peculiaridades do campo temático, em franco processo de redefinição de contomos, surgem problemas com a aceita- 
ção de originais por periódicos de circulação internacional. A Epidemiologia não escapa deste quadro. Acrescente-se a isto a importância, muitas vezes meramente regional, do produto acabado da investigaçâo epidemiológica, que encontra difícil acolhida. Para contornar estas dificuldades, faz falta um projeto de divulgação nacional, com linha editorial que acolha trabalhos que expressem o debate real, com todas suas incertezas e indefinição aparente. Há que encontrar mecanismos que ampliem a divulgaçāo da chamada literatura fugidia, composta de mimeografados, apostilas e documentos de círculação restrita, tão freqüentes em nossa área. Tudo isto sem perder o rigor e a seriedade com que deve ser tratada a questão do que pode ser considerado produção científica!

A questão já havia sido tratada por Donnangelo (1983) em trabalho que, a vôo de pássaro, configura a produção em Saúde Coletiva no Brasl na década de 70. Considera que a formalização das questōes emergentes do processo atual da Saúde Pública, apenas através de textos escritos, parcializa a óptica em que se apreende $o$ conhecimento produzido. Assinala que o movimento caminha por direções cujos agentes não são redutíveis a um conjunto de autores. Ressalta o papel político do conjunto de saberes que suportam as práticas das diversas categorias profissionais e dos setores sociais. Apesar da enorme importância política destes saberes, a produção formalizada nos textos escritos é predominantemente acadêmica.

Este problema não é exclusivo da Epidemiologia nem do Brasil, é praticamente sentido no conjunto das disciplinas que conformam a Saúde Coletiva em toda a América Latina. Tem merecido esforços especiais de compilação, inclusive da literatura fugidia, coordenados pela OPAS/OMS. Nesse esforço, merece destaque a Bibliografia Latino-Americana sobre Ciências Sociais em Saúde (OPS/OMS, s.d.). Esta, editada sob a responsabilidade de Badglei, Bravo e Garcia, foi analisada em reunião do Comitê de Pesquisa Médica da OPAS, San José, Costa Rica (PAHO, 1980) e, posteriormente, aproveitada por Nunes (1985) em seu interessante resumo da atividade da área, discutido na reunião de Cuenca, Equador, de 1983. Dos 1.663 trabalhos compilados, em três décadas, 1950 a 1979 , a Epidemiologia (ou Processo Saúde-Doença como é ali chamada) participa com $469(28,2 \%)$, proporção que se manteve relativamente estável no periodo. É importante reter que a Epidemiologia responde por pouco menos de $1 / 3$ da produção formal da área de Saúde Coletiva, o que não é desprezível. O mesmo trabalho de Nunes (1985) analisa a produção segundo subtemas, com $30 \%$ dos trabalhos sobre o processo saúde-doença, sociedade e determinantes sociais, 
$27,8 \%$ em aspectos sociais das doenças mentais e $23,3 \%$ em nutrição, crescimento e desenvolvimento. Os demais subtemas, inclusive aspectos sociais das doenças infecciosas e doenças tropicais, participam em pequena proporçăo. Isto leva, imediatamente, a supor que os critérios de inclusão, pelo próprio título do trabalho, excluíram grande parte da produção da chamada Epidemiologia Convencional. A participação da Epidemiologia, consideradas todas as suas vertentes, deve ser ainda maior do que os $28,2 \%$ assinalados. Faz falta um quądro da década de 80 , o que, do que se tem notícia indireta, já está sendo desenvolvido pelo próprio Nunes.

Quanto ao programa de edição de livros, dados dos últimos 10 anos, analisados por Buss (1989), mostram que, dos 105 títulos publicados, a Epidemiologia responde por $7(6,7 \%)$. Deve estar presente em outras categorias, como saúde do trabalhador, saúde mental e saúde materno-infantil, porém fica bem distante das $16(15,2 \%)$ edições relacionadas com Políticas de Saúde. Possivelmente não é por outro motivo que a previsão do programa editorial da Abrasco para 1989-1990 inclui 50,0\% de textos de Epidemiologia entre os dez títulos apoiados. Estas informações, bem como o restante do Programa Editorial da Abrasco, constam de documento preparado por sua Secretaria Executiva (Abrasco, 1989).

Apesar dos esforços, especialmente da Abrasco, os queixumes quanto à incipiencia da linha editorial de toda a Saúde Coletiva têm sido constantes. Ver, a propósito, os documentos de apoio e os relatórios dos Seminários de Avaliação do Programa de Saúde Coletiva: Pellegrini Filho et al (1986), Abrasco (1986), Finep (1988), Abrasco (1988).

As mesmas dificuldades encontradas quanto à produção formal e à literatura fugidia revelam-se quanto às informações produzidas a nível dos serviços. Existem esforços de divulgação destas a nível nacional, estadual e municipal, através de ministérios, secretarias de saúde e outros órgãos. Estes esforços nunca foram, de fato, sistematizados, analisados criticamente e colocados amplamente à disposição dos pesquisadores. As coleçōes são descontinuadas sem a menor cerimônia diante de qualquer problema orçamentário ou político surgido. Para citar apenas dois exemplos de nível nacional: IES - Informações Epidemiológicas da Sucam e Informe Epidemiológico da Snabs, ambas do Ministério da Saúde. As dificuldades quanto ao uso das informações da Dataprev, do IBGE e de outros ministérios como o do Trabalho já são amplamente conhecidas e vivamente criticadas. Estas dificuldades foram analisadas e, novamente, criticadas em Seminário de Informação em Saúde Coletiva (Abrasco, 1988). 
Uma iniciativa importante, o programa "Reunião, Análise e Difusão de Informaçôes sobre Saúde", Rádis (ENSP-Fiocruz), criado em 1982, especialmente através da publicação Dados, tem buscado a divulgação do conhecimento epidemiológico entre profissionais e a população em geral (ENSP, 1990).

Quanto à divulgação das teses e dissertações dos programas de pós-graduação da área de Saúde Coletiva como um todo, aproximadamente 90 são defendidas anualmente e apenas $2,7 \%$, transformadas em livros (Abrasco, 1989). Os esforços da Abrasco, através dos encartes de seu Boletim Bimensal e da Faculdade de Saúde Pública da USP, não recobrem o universo de produção, onde, obviamente se incluem textos de Epidemiologia. Os bancos de teses das agências financiadoras, especialmente CNPq, e das universidades, USP, por exemplo, são esforços promissores.

Um último ponto deve merecer a atenção dos cientistas dos países subdesenvolvidos, de todas as áreas do conhecimento. $\mathrm{O}$ mundo moderno, diante da perspectiva de uma sociedade informatizada, impõe questionamentos que não são triviais. O rápido desenvolvimento da tecnologia, com os microcomputadores, a transmissão remota de imagens, vídeo, discos-laser, novos mecanismos de armazenagem, impöem decisōes políticas quanto aos rumos a seguir para impedir a ampliação da hegemonia dos países desenvolvidos e da brecha tecnológica (Roberts, 1988). Há de ser traçada uma estratégia global para conter esta tendência, que incluirá, forçosamente, uma estratégia regional da Epidemiologia Brasileira.

\section{ESTRATÉGLA}

A estratégia própria da Epidemiologia Brasileira deve ser traçada em conjunto com a das demais áreas da Saúde Pública. Em vista dos resultados já conseguidos, o projeto editorial da Abrasco deve ocupar o centro do palco. Acredito que deve ser o ponto central de atuação da Abrasco: a consolidação da entidade passa pela de sua linha editorial e de seus congressos.

A linha editorial da Abrasco é orientada competentemente para co-edição de livros. O Boletim e os Catálogos já estão consolidados. Os Estudos de Saúde Coletiva, em seu quinto volume, merecem uma discussão mais detida, assim como os Textos de Apoio. A proposta de consolidar a linha editorial da Abrasco passa por um amplo debate quanto a seu formato. Os Textos de Apoio já compóem séries especiais, por áreas temáticas, devem seguir nessa linha. Os "Estudos" mereceriam maior atenção: a serem mantidos como estão, com alguns artigos e relatórios de reuniōes e seminários de todas as áreas da Saúde Coletiva, 
são amplos demais num momento de esforço de consolidação da linha editorial e da própria Abrasco. Acredito que se deva transformar em série especial, semelhante às dos Textos de Apoio, as publicaçōes relativas a reuniōes e seminários; contendo os documentos básicos e os relatórios, à semelhança da série de Informes Técnicos da OMS. Esta proposta redunda numa alteração da linha editorial dos Estudos de Saúde Coletiva que poderiam ser transformados em Revista de Saúde Coletiva (Abrasco), acolhendo fundamentalmente artigos originais e revisōes ou atualizações encomendadas pelo corpo editorial, exigindo a composição de subcomitês, por área temática.

Outro aspecto a ser cogitado é o da sistematização da divulgaçāo das informaçōes originadas nos serviços. Devia-se tratar de pôr ordem no quadro caótico que se apresenta no momento. Ministérios, Secretarias e outros órgãos deveriam ser induzidos a regularizar, uniformizar e compatibilizar suas publicações, tratando esta questão com mais seriedade e estudando a viabilidade de auto-sustentação financeira de suas publicações, que as torne menos vulneráveis às mudanças políticas. Elemento importante da divulgação da produção científica é representado pelos Congressos, com ênfase na apresentação de temas livres.

Propositalmente, por último, obvianente não menos importante, especial atenção deveriam merecer as tendências modernas de circulação da informaçăo científica, estabelecendo estratégias de ação da Abrasco em conjunto com as demais entidades científicas brasileiras.

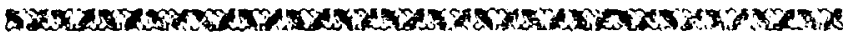

Despite several proposals concerned with the plans of development of Epidemiology, there is, already a great discussion over the object of this subject. The recent development of a "new" Epidemiology has often been questioned as a tool adequate enough to give bases to the projection and operation of contemporaneous health centers. Epidemiology as a scientific subject has a peculiar character: the social determinations attached to problems and urgency of answers. The academic environment, though a privileged place, is not the exclusive producer of Epidemiologic knowledge. Apart from papers and books produced by the academic work, we must consider the "marginal" writings so common in such area of knowledge.

Also we have an incipient systematic divulgence of

Cadernos de Saúde Páblica, RJ, 6 (3): 319-329, jul/set, 1990 
relevant epidemiological information originated from the health centers. Even the academic work such as thesis and dissertations are not well divulgated. The Brazilian editorial policy of ABRASCO (Brazilian Association of Colective Health) has the most important role in the divulgence and definition of the lines of Epidemiology.

Key words: Epidemiology, Epidemiological production, Epidemiological divulgence.

\section{REFERÊNCIAS BIBLIOGRÁFICAS}

ABRASCO - Reunião de avaliação do Programa de Salide Coletiva FINEP/CNPq. Estudos de Saude Coletiva, n: 4: 69089, 1986.

ABRASCO - 2: Seminário de avaliaçăo do Programa de Saúde Coletiva: documento preliminar, subsídios para avaliação. Mimeo, 1988.

ABRASCO - Seminário "Informação em Saúde Coletiva: uma proposta de integraçảo institucional": Relatório Final. Estudos de Saúde Coletiva, n: 5: 139-141, 1988.

ABRASCO - Educaçấo e Pesquisa em Saúde Coletiva no Brasil: situação atual e proposta de trabalho (1987-1989). Mimeo, 1989.

ALTHUSSER, L. - Sobre o trabalho tebrico. Ed. Presença, Porto, 1978.

BREILH, J. - Epidemiologfa: Economfa, Medicina y Polftica, Publ. Sespas, Santo Domingo, 1980.

BRUYNE, P.; HERMAN, J. \& SCHOUTHEETE, M. - Dinâmica da pesquisa em ciências sociais: os polos da prática metodológica. F. Alves, Rio de Janeiro, 1977.

BUNGE, M. - Epistemiologia. Ed. da USP, São Paulo, 1980.

BUSS, P. M. - Produção Cientifica em Saúde Coletiva no campo editorial. Cadernos de Saúde Pública (Ensp), 1989.

DONNANGELO, M. C. F. - A pesquisa na área da Saúde Coletiva no Brasil - a década de 70. Ensino da Saúde Páblica, Medicina Preventiva e Social no Brasil (Abrasco), vol, 2: 17-35, 1983.

ENSP/RADIS - Reuniāo, Análise e Difusāo de Informação sobre Saúde. Mimeo, 1990.

FINEP - Programa de Saúde Coletiva. Mimeo, 1988.

HOLLAND, W. W. \& KARHAUSEN, L. - Health Care and Epidemiology, Henry Kmpton Publ., London, 1978.

MENDES GONÇALVES, R. B. - Tecnologia e organizaçăo social das práticas de saúde: características tecnológicas do processo de trabalho na rede estadual de Centros de Saúde de São Paulo. Tese de Doutoramento. Faculdade de Medicina da USP, São Paulo, 1986.

NAJERA, E. - Usos y perspectivas de la Epidemiologia en la investigacion, in OPS Usos y perspectiva de la Epidemiologta p.p.: 109-132. Public. N: PNSP 84-87, OPS, Washington, 1984.

NUNES, E. D. (organiz.) - As Ciências Sociais em Saude na América Latina: tendências e perspectivas. Public. OPAS, Brasilia, 1985.

OPS/OMS - Bibliografia Latinoamericana sobre Ciencias Sociales aplicadas a Salud (org. por BADGLEI, R. GF.; BRAVO, G. \& GARCIA, J. C.), (s.d.). 
PAHO - Report of the Advisory Committe on Medical Research: Working Group on Research in the Social Sciences Meeting, 48p, San Jose, 1980.

PELEGRINI FILHO, A.; ALMEIDA, C.; SZKLO, F.; VIACAVA, F.; CORDEIRO, H.; NICOLETTI, L.; PACHECO, M.; BUSS, P. M. \& MENDES GONÇALVES, R. B. Pesquisa em Saude Coletiva. Estudos de Salde Coletiva, n: 4: $39-50,1986$.

ROBERTS, K. H. - The library in tomorrow's society: a literature review. Publications IDICT, 1988. 